\title{
Envisaging Teacher Spatial Competency Through the Lenses of Situated Cognition and Personal Imagination to Reposition It as a Professional Classroom Practice Skill
}

\author{
Vicky Leighton
}

\begin{abstract}
This chapter examines the complex phenomenon of teachers' spatial interactions in their learning environments. Its goal is to examine concepts and theories that might inform a working conceptual framework. Building on recent studies that question how school environments can influence teacher behaviour, spatial concepts as well as architectural and cognitive psychology theories are examined to explore the dynamic and mutually dependent relationship between teachers and learning spaces. A new concept of 'situated environmental imagination' is devised as a conceptual explanation for teacher spatial competency; it also provides practitioners with the means to evaluate and observe space-related skills in classroom action settings. This approach pursues a non-linear understanding and analysis of space and teacher practice that blends architectural and educational perspectives, resulting in an argument for the inclusion of spatial competency as an important professional skill that has the potential to enhance student learning.
\end{abstract}

\section{Preface}

In setting up a theoretical conceptual framework in which to explore a teacher's spatial competency, it has become necessary to understand the relationship between the built environment and human behaviour. The environment is acknowledged by many teachers as one minor element of a battery of tools to educate others, however, it is seldom placed front and centre when considering the transaction between teaching and learning. But it should be. Across the globe, school environments are the focus of government policy and the recipients of systematic, significant investment. This has evolved as a strategic response to narratives that are recasting what effective teaching and learning should be for post twentieth-century work and education (Byers, Mahat, Liu, Knock, \& Imms, 2018; New Zealand Ministry of Education,

\footnotetext{
V. Leighton $(\varangle)$

Melbourne Graduate School of Education, The University of Melbourne, Melbourne, Australia e-mail: vleighton@student.unimelb.edu.au; Vicky.Leighton@churchie.com.au

Anglican Church Grammar School, Brisbane, Australia

W. Imms and T. Kvan (eds.), Teacher Transition into Innovative Learning Environments, https://doi.org/10.1007/978-981-15-7497-9_21
} 
2014; OECD, 2013). Significant public funding in new school buildings has been invested to promote teaching and learning that is characterised by critical thinking, collaboration, problem-solving, communication and creativity. Beyond these investment programmes, it is recognised that most teachers are situated in a classroom, new or otherwise, which remains the key environment in which instructional learning is conducted. These teachers interact with their classroom space both consciously and unconsciously. They are taught how to teach curriculum content and pedagogy, however, until very recently they are rarely trained on how to use space to advance and support their teaching and maximise learning experiences for students.

Through an exploration of historical behavioural sciences, ecological psychology and the more recent emergence of cognitive psychology supported by neuroscience, this chapter argues that a teacher's behaviour within a classroom 'action' setting is a mediated 'imaginative' response between their real-time, 'situated' interaction with the environment itself, and the social world. This behavioural response can be recognised as a part of a teacher's professional practice and as a teaching skill.

This reimagining of the roles played by both people and the built educational space challenges educators and designers to investigate in-depth what already occurs in traditional or established classrooms and to consider the impact of teacher situated cognitions on these and innovative learning environments. Where sequences and patterns of behaviour are encouraged by the built environment and are consciously or unconsciously acknowledged, these in themselves become the experiences of educational places that feed an individual's professional practice. They shape a teacher's spatial behaviour which in turn has a direct impact on student learning.

The impact of this idea is manifold. It suggests that educational settings are places that shape what people do, how they engage with one another and how they consequently contribute to the construction and deconstruction of teacher identities. It implies that the built environment (the classroom), which provides a framework for behaviour, allows for a future that can be purposefully constructed and manipulated, acknowledging that the contextualised environment itself is also shaped through this interchange. It invites exploration into the connections between student learning and teacher spatial skills and engagement. It suggests that teachers can be taught to hone their spatial practices to enhance learning through training and intervention, recognising that all teachers possess spatial skills. This approach puts the impact of a teacher's spatial professional practice squarely in the centre of the learning and environment debate.

What follows is a brief synopsis of key cognitive concepts and theories that are examined to conceptualise teacher spatial competency (TSC). These are used as a source of insight rather than empirical study. It is acknowledged that a range of deliberate parameters has been imposed; rather than an in-depth exposition of architectural design or cognition theories, a range of general agreements from these areas of human science are accepted and a lens of educational professional practice applied. This has enabled a conceptualisation of the phenomenon known as teacher spatial competency and provided a framework for research. 


\section{Introduction}

Although systematic studies examining how school architecture informs teaching and learning are rare (Byers, Imms, \& Wheaton, 2015; Higgins, Hall, Wall, Woolner, $\&$ McCaughey, 2005), research focused on learning spaces is gaining momentum. Fine-grained studies examining learning and learning environments such as these are finding evidence that suggests these two educational components share a binary relationship that somehow incorporates elements of duality and dichotomy. They argue that teachers and learners occupy designed educational spaces that do inevitably influence the teaching and learning cycle, and that this relationship is complex and not always articulated or understood. This leads to key questions for educators and architects which centres on what spatial knowledge or skills teachers need to successfully utilise traditional or innovative learning environments to positively impact learning outcomes. It seems clear that a blend of architectural, educational and social theory is necessary to understand, describe and interpret the complex concepts at play, and to develop a conceptual framework to underpin teacher spatial competency research. Furthermore, clarity is required around the definition of the key term 'TSC'. For this research, it is proposed that a spatially competent teacher is a teacher that deliberately and purposefully utilises (through their professional practice) the attributes of a classroom and surrounding environment (in their 'place') to deliver specific pedagogical goals. As learning goals change (these are highly responsive to context), the teacher also changes the utilisation of the space to enhance student learning experiences (this a result of their thought processes). This chapter will examine the three key elements, teacher place, practice and thinking, embedded in this broad definition.

\section{Teacher Place}

The study of human behaviour gives us an insight into understanding human activities, attitudes and values. When it is accepted that the environment has an impact on human behaviour, this allows for the theorisation of human spatial interactions through a range of cognitive processes including motivation, perception, cognition and affect. Differentiating between the actual, real or objective world and the phenomenological world that is perceived either consciously or unconsciously also offers the potential for new conceptual frameworks to understand and observe how humans are impacted by places and space.

\section{Architecture and Phenomenology}

Although this is not a phenomenological argument, some of the principles associated with its approach to qualitative research apply to the exploration of teachers' spatial 
perspectives and competency. The relevance of a phenomenological approach is also acknowledged when considering the philosophical roots from which it arises (Moustakas, 1994). Phenomenologists seek to develop direct explications of ordinary life and human experience. These experiences often go unnoticed as they are so embedded in our way of living and thinking and are unique to each person. To borrow from Pointon and Kershner (2000):

Further, at a perceptual level, it has to be recognised that it is hard to understand another person's experience of the environment, even if one can measure certain objective features. As Howe (1984) remarks, 'each person's experiences of an environment are unique and constantly subject to variation, largely because people learn from their own experiences. Many factors connected with individual development and learning, including perceptual sensitivity, personality and temperament, combine to ensure that however uniform an environment might appear to be, people's actual experiences differ very considerably' (p. 96).

Architecture phenomenological research emphasises and interprets the lived, human experience of everyday buildings in everyday lives. That is a corporeal or bodily engagement with space expressed via human action in synchronisation with the physical environment. The two elements, in this case teacher and learning environments, 'interanimate each other' (Casey, 2009), providing a tantalising inference of potential impact on teacher practice and student learning. If a teacher is 'interanimated' by their learning environment, this implies that the interaction can be positively manipulated to impact student learning.

Several academics take this perspective further. Oblinger (2006) theorises that learning spaces arbitrate social and relational teaching with learning conventions and builds an argument that this mediation is only one factor in a complex range of contextual variables that inform learning outcomes. These factors include, but are not limited to, school context, culture and profile, pedagogies, curriculum, technologies, learning environment and aesthetics, as well as community members themselves. A study of Lefebvre suggests this mediation is social interaction (1991). It is argued that teacher spatial experience is, therefore, a lived dynamic where there is a reciprocal engagement with the environment. This is significant at it suggests these contextual interactions influence a teacher's professional practice. It can be concluded that occupiers and space are mutually dependent and ever-evolving.

\section{Architectural Vocabularies and Literacies}

Researchers have wrestled with this dynamic relationship. Fisher questions why teachers appear to ignore their learning environments as a pedagogical tool, arguing that 'it is in the school campus that we all begin to learn how architecture is lived and experienced and develop our architectural vocabularies and spatial literacies' (Fisher, 2004, p. 37). Fisher's observation underpins the focus of this chapter which, assuming improved student learning is the educator's goal, argues that physical learning environments cannot be ignored by users. It may be they are not being ignored; albeit, 
it is possibly a subconscious action that sees teachers adapt and change their practices and their environments in subtle ways, even marginally, to effect better learning. Furthermore, architecture and the built learning environment should not be viewed as a language, but more correctly represents a set of vocabulary and associated contexts. This implies less a need to decode or interpret, but rather a recognition of how built learning environments 'speak'. Individuals consciously and subconsciously recognise a building's voice because they provide identifiable symbolic perspectives that refer to their prior experiences and encounters; they exist in their present, and they reflect forward through the multitude of interactions with all who use them. By their very presence the built environment reacts to the past as well as the 'present' to either invite a new way of operating or 'set' the future to mirror its habitual self. So, this chapter argues less the notion of teacher spatial incompetency, and more the need to theorise and understand the existence of various levels of existing teacher spatial competencies.

\section{'Thought-Like' Architecture, Culture and Context}

If this is an accepted notion, the learning environment itself has the possibility of becoming involved in thought or be 'thought-like' in that it represents ourselves, but our objectives are learnt from it; the individual and the architecture are therefore constantly reimagined (Fig. 1). Hays puts it this way; 'Architecture is not a language. Rather, architecture summons into appearance ways of thinking about the world that is otherwise unavailable; it is a particular mode of thought, one irreducible to other ways of thinking...' (Hays, 2016, p. 205). In this context, the place becomes representational of schools' complex societal structures, purpose and culture.

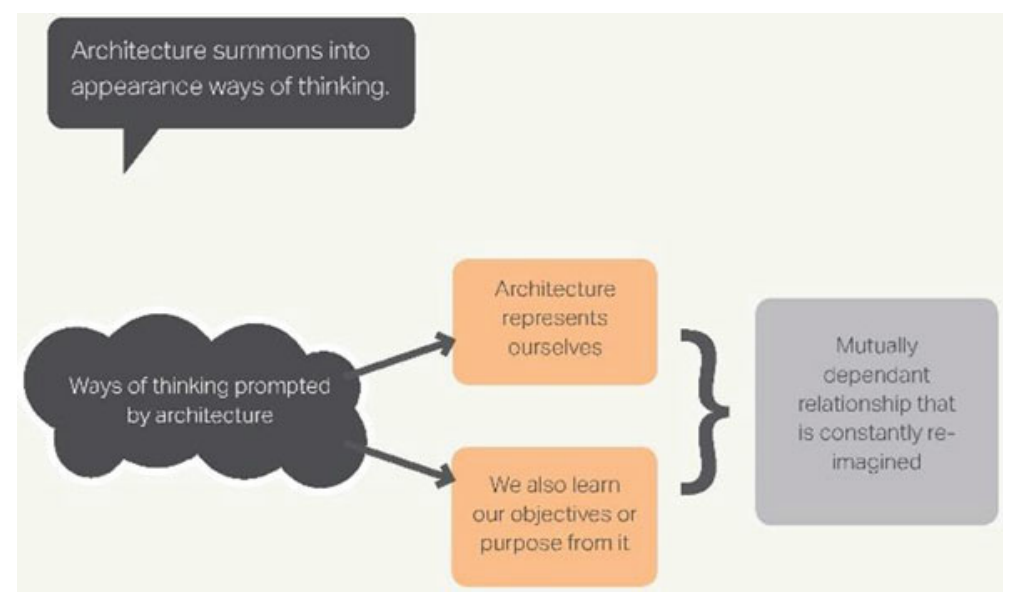

Fig. 1 'Thought-like' architecture 
There is a mutual dependence where the built environment becomes involved with its own purpose, for example in the adaption and response of pedagogy through its interaction with the teacher. It is informed by ideology, patronage, designers and users, but can also be understood to be ideological in its own right. It is not entirely determined by its context, but through its very existence, it connects these elements and becomes self-determining. Acknowledging the theorisation around social materialisation (Hays, 2016), it is understood that here there is an epistemological, constructivist claim; that is, something is known about education and learning through the architecture of schools, and; something is known about the nature of learning through the classroom.

Related cognitive factors are also used to conceptualise the activity of teaching and it is recognised they can directly influence a teacher's approach to their professional practice. Drawn from the synthesis of his meta-study (2009), Hattie (2012) termed these factors as mind frames which he categorised into eight key ways of teacher thinking that significantly impact student learning; 'the impact(s) in our schools relates to how we think' (p. 159). In terms of learning environments, 'thought like architecture' confirms the importance of school culture and context to a teacher's thinking (or mind frame) and professional practice.

\section{Teacher Practice}

To further consider the impact of these ideas, a broad lens of spatial practice and representation should be applied. Massey recognises space as the 'product of interrelations as constituted through interactions'; 'as the sphere in which distinct trajectories coexist' and 'always under construction' (Massey, 2005, p. 9). In an exploration of Lefebvre's seminal work 'Production of Space' (Lefebre, 1991), Benade (2017) acknowledges the theory that space is socially produced (Tyack \& Tobin, 1994); that perceptible and imperceptible qualities of space act as a critical and productive link between the built environment and daily lived experiences. Benade draws on Merrifield's (2006) suggestion that 'spatial practices structure lived reality' (p. 3), inviting further exploration of how occupants and users of space(s) create their own lived realities.

The study of human behaviour recognises that humans operate as individuals who enact roles within a range of complex and interlinked social systems that influence behaviour and social norms. These social contexts are embedded in behaviour patterns and are intrinsically linked to their terrestrial environments. For example, teachers behave as purveyors of knowledge and skill within the setting of their work. The way daily activities are carried out is part of a person's culture; their role in society, their beliefs, attitudes, prior experiences, competencies and purpose. These behaviours are embedded within the individual's environment.

In considering the influence of the setting itself, Lang (1987) argues that architecture is 'culture-bound'. Hays describes this idea as architecture that is a cultural and social representation, or architecture as 'mode of knowledge' (2016). Moreover, he 
argues that what might be known or present in one era, may not be available to another. This results in a cognitive, imaginative response that mediates every experience with the built environment. Whilst this is being further nuanced by neuroscientists and cognitive psychologists, it is important to acknowledge that this approach accepts the environment to be highly influential on human behaviour.

Consideration should also be given to Lefebvre's triadic of spatial practice, that is; representation of space (conceptualisation); spatial practice (material, lived experience) and representational space (symbolic, mnemonic). These combine into a social production of space; 'the triad of the perceived, the conceived, and the lived' (Lefebre, 1991, p. 40); or 'the three moments of perception, conception and living (which) are simultaneously conscious and unconscious' (Benade, 2017, p. 6).

Furthermore, if it is accepted that school culture represents itself to itself through its built environment, it follows that school communities learn in part about themselves, the function of their school culture, and their purpose, through the education buildings themselves. Moore (1986) in a study that explicitly questioned the interactions and interdependence between social contexts, the architectural environment and human behaviour, concluded that the physical environment 'does not — and maybe cannot-have an independent impact' (p. 227), thereby implying the dependency on other factors.

Architectural and educational research often advocates for training teachers to better use spaces (Woolner, Clark, Laing, Thomas, \& Tiplady, 2012). Whilst some visualise this as a parallel, linear interaction of space and practice (Fisher, 2005; Tanner, 2009) whereby the spaces they design somehow bring about contemporary teaching and learning practices (Benade, 2017), it is also important to imagine it as a circular interdependence between spaces and people. This more interactive approach emphasises spatial-skill collateral that is arguably already present within teaching professional practice. If accepted, it can be concluded that teachers are not spatially illiterate, rather we simply don't have mechanisms to recognise their actions or to help use them to improve practice.

\section{Environmental Competency}

The term 'spatial competency' has its genesis in the work of Lawton who coined a related term 'environmental competency' in a study examining the environmental needs of the elderly within the context of 'man-environment relations' (1977).

In a review of the literature, many environmental and ecological psychology studies take as their foundation psychologist Lewin's (1936) formulation of behaviour; that is behaviour is the function of the person and their environment. When applied to teacher spatial competency, teacher spatial behaviour can be seen to be dependent on the functional relationship between the person and their school environment. Indeed Lawton used Lewin's ecological equation, $B=f(P, E)$, to devise a schema that proposes competence as 'function' in relation to the 'environmental press' of a place. Lawton defines competence as a term that describes 'essentially 
what lies within the person' (1977), including a broad set of attributes such as their health, mental capacity and so on. 'Environmental press' he uses as a term to describe elements of a place that promotes or activates behaviour in 'some individuals'. The key point he makes is that the greater the environmental competence of an individual, the less constrained they are by their environment, played out by a demonstration of 'behavioural freedom' (Lawton, 1977). This approach is relatively easy to understand when considering the physical capacities in the elderly, such as motor skills and can be adapted to the concept of cultural behaviour in schools and spatial competency of teachers.

\section{Spatial Competency in Teachers-Early Conceptualisation of the Concept}

If it is accepted that most spaces, or learning environments, have possibilities that can be used by a teacher to impact learning, it is often supposed that a critical barrier to teachers' fully utilising their physical learning environment is their lack of environmental 'competency' (Lackney, 2008).

Spatial or environmental competency as a term has since become common currency when discussing how teachers behave within and use space. To date, it has implied a graded scale of behavioural competence that allows some individuals to be highly proficient when interacting with space's affordances, whilst others somehow seem to lag. A teacher who is more adept at manipulating their environment to enhance learning, demonstrated through flexible and facilitated spatial interventions within a classroom, is a good example of perceived 'responsive' spatial competence. The counter to this is the spatially 'incompetent' teacher who supposedly is unable to purposely use an instructional space. Lackney's early study promoted this line of thinking through his 'levels of environmental competence at the individual scale' table (Fig. 2), that scaled and categorised teachers from 'highly proficient' to 'lack of proficiency' (Lackney, 2008).

This spectrum is, however, problematic, not least because it should be recognised that all teachers are situated 'actors' using and responding to space as part of their teaching practice. The reality of this interaction is that all teachers uniquely respond to a large range of confounding variables that influence their output. Furthermore, the idea of scaled competency (in this context) has the potential to lead to a simplification of the concepts under review, and the erroneous conclusion that the classroom (as the built component) is the sole determinant in the teaching and learning transaction; that the classroom is the determining factor (Nair, 2011). This is where architectural probabilism or possibilism comes into play; the suggestion that it is possible to calculate likely teacher behaviour in response to built stimuli, but this would be erroneous and miss the fundamental importance of this conceptual framework. 


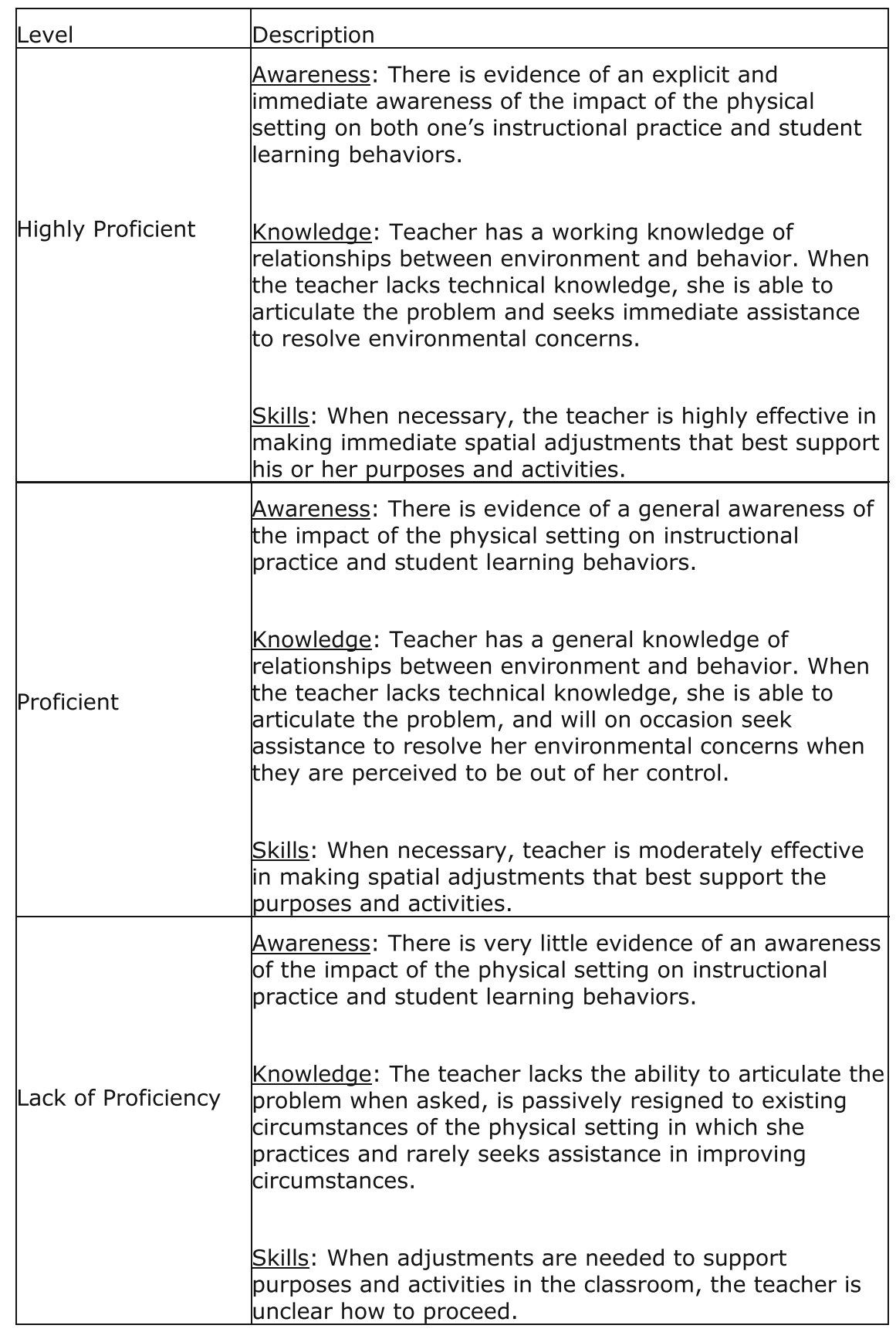

Fig. 2 Levels of environmental competence at the individual scale (Lackney, 2008) 
Many designers have made very strong assumptions that the spaces they create will, in themselves, lead to change...It is highly questionable to claim a design will have particular behavioural outcomes without first taking into consideration the predispositions and the motivations of the population concerned (Lang, 1987, p. 102).

It should be understood that architects, designers and educationalists should not rely on what might happen as a result of design in school settings (Lippman, 2010), but rather in what does occur every day. Teacher spatial competency is not deterministic; assumptions can be made, and trends established, but the variables involved discounts absolute certainty. To be clear, teachers need to have observable spatial capabilities, however, these should be relative competencies that are not hierarchical and should be linked to student learning. This new approach puts the teacher metaphorically speaking at the front of the classroom and students in the centre of the action. This is important as architectural determinism, or conversations that prioritise design tends to isolate teachers and consequently disable them in terms of changing their spatial practices, with consequences for student learning experiences.

\section{Teacher Thinking}

\section{Environmental Psychology}

The work of early psychologists reframed the nature and influence of the humanenvironment relationship through a substantial body of research resulting in a significant literature of writings. Koffka's seminal work Principles of Gestalt Psychology (1935) was one of the first to distinguish between geographical and behavioural environments. Amongst others, this was followed by Lewin's (1936) formulation of behaviour. It wasn't however until the early 1950s that psychologists and other behavioural scientists began to investigate in depth the interaction between the built environment and human behaviour. This represented a new field that is, respectively, known as architectural, ecological or (and for the remainder of this chapter) environmental psychology.

At a fundamental level, environmental psychology research assumes a correlation and interdependence between environments and behaviour. Goldhagen points out, 'The built environment constitutes the foundation upon which our past, present, and future selves are constructed' (2017, p. 88).

Gibson (1966) theorised 'potential' and 'effective' environments for behaviour (which specifically considered what a person pays attention to). Weinstein (1981) used an environmental psychological approach to person-environment relations and suggested that the environment communicates 'direct' and 'symbolic' effects on students. Soja (1989) asserted that the discipline of 'critical human geography', a branch of critical social theory, allows for new interpretations of social history seen through the lens of spatial critiques. Soja (1989) pushed this concept suggesting 
that 'just as space, time, and matter delineate and encompass the essential qualities of the physical world, spatiality, temporality, and the social being can be seen as the abstract dimensions which together comprise all facets of human existence' (p. 25). The abstract dimensions associated with temporality and space explains the complexity of the variables involved (Massey, 2005). Kirk (1990) introduced the consideration of the personal environment with the implication of the importance of personal experience and contexts, which naturally leads to the examination of teacher mind frames and behaviours. These personal experiences take place in classrooms where 'hegemonic pedagogy', or teaching practices that reflect and perpetuate current regimes, is the dominant paradigm (Hildebrand, 1999). Gislason (2010) used behaviour setting theory that assumes 'behaviour is a function of the person and the environment' (Swartz \& Martin, 1997, p. 6). He based his theory on Owens and Valesky's (2007), and by deduction after Barker and Gump (1964), conceptual school climate model. Gislason used it as a tool that 'accounts for the relationship between school design, teaching and learning' (2010, p. 128).

The impact of this field of research has been far-reaching. For example, the traditional theoretical viewpoint held by architects, landscape architects and designers proposed that the components of the built environment critically related to each other, rather than human experience. This led to the belief that if the human experiences within a space were different to the designed intention, the fault was 'user error' often attributed to ignorance, lack of education or knowledge (Perin, 1970). Environmental psychology challenged these long-held beliefs. New knowledge about the significance of the environment in our lives has become a central part of the critical discourse about human behaviour.

\section{Situated (or Embodied) Cognition}

This research therefore moves beyond a traditional linear understanding of human cognition and experience of environment towards a more interlinked approach that emphasises an associative, non-conscious element that has its basis in the idea of the human physical presence within a space that provides 'situated' or 'embodied' cognition (Barsalou, 2008; Goldhagen, 2017; Johnson, 1987). This idea is important in that it recognises that human cognition and 'place' directly impacts decision-making and ultimately action; that is, human behaviour emerges from the interaction of the physical self (with its unique capabilities) situated in a place, with the opportunities for action offered by that place, at any given time.

It is helpful to consider cognition as the many processes by which people understand, interpret and organise sensory, social and internally generated data for their use. Cognitive psychologists who are advocates for situated cognition argue that the human mind is shaped by the body (human embodiment); and that the human body is shaped by the environment (Barsalou, 2008; Goldhagen, 2017; Johnson, 1987; Robbins \& Aydede, 2009). This situated relationship reveals how conscious and subconscious cognitions build up mental schemas or patterns of association. This 
organisation of data is generated by a range of inter-sensory impressions (involving more than one sense). Individuals have innumerable schemas that are interlocked with the environments in which they live and experience life.

\section{The Potential Environment}

Before unpacking these ideas further, it is necessary to explore the framework of the environment itself as a place of potential efficacy. The key to unlocking this potential lies in understanding why a classroom environment embedded with a variety of affordances (that suggest certain behaviours) is not always enacted upon by its users; why some people appear to be more spatially active in their professional practice than others. This is summed up by Lang in this way; 'Not all opportunities for action are perceived by an individual, nor are all the opportunities that are perceived acted upon' (1987, p. 80).

The concept of a 'potential' environment (Gibson, 1977), in which several possible actions can be played out, is based on studies that explore how humans relate to situations and place. The concept is an abstraction, but it is based on the mental images that are generated when interacting with the environment. This is directly relevant to how a teacher reacts to their classroom in that their behaviour is situated in their cognitive response to the place, which in turn opens (or limits) their responsiveness to its affordances. Their mental image, or imagination, bridges the gap between perception and understanding. Thoughts become material in a person's response, and the potentials inherent to an environment acknowledged.

This implies space can be defined as a responsive (not flexible) partner. Teachers are very familiar with the term 'flexible learning environment', but their experiences of these spaces are often mixed (Benade, 2017; Bradbeer, 2016), and not necessarily aligned to the designed intention. To be flexible implies an elasticity where a form or object always returns to its original state (Fig. 3). This is not the commonly intended outcome for investment in new learning environments, that is for professional practice to be unaffected by the purposely designed space. A building that reacts to something/somebody, that can evolve, converse (give a response to...) and possibly learn (Lippman, 2010) is a better alternative. Lang says 'What architects create is a potential environment for human behaviour; what a person uses and appreciates is his or her effective environment' (1987, p. 75). Responsive, adaptive teachers and environments, therefore, have the potential to work together in a new way for the benefit of student learning (Saltmarsh, Chapman, Campbell, \& Drew, 2014).

The traditional view that human behaviour is simply a 'use' signifier that contributes to the design of a place short changes both architects and the clients they serve. It is often thought that the study of behaviour simply adds to the knowledge about the purpose of a building, however, this is a new emphasis that argues that it has the power to change the very nature of that knowledge (Lang, 1987). 


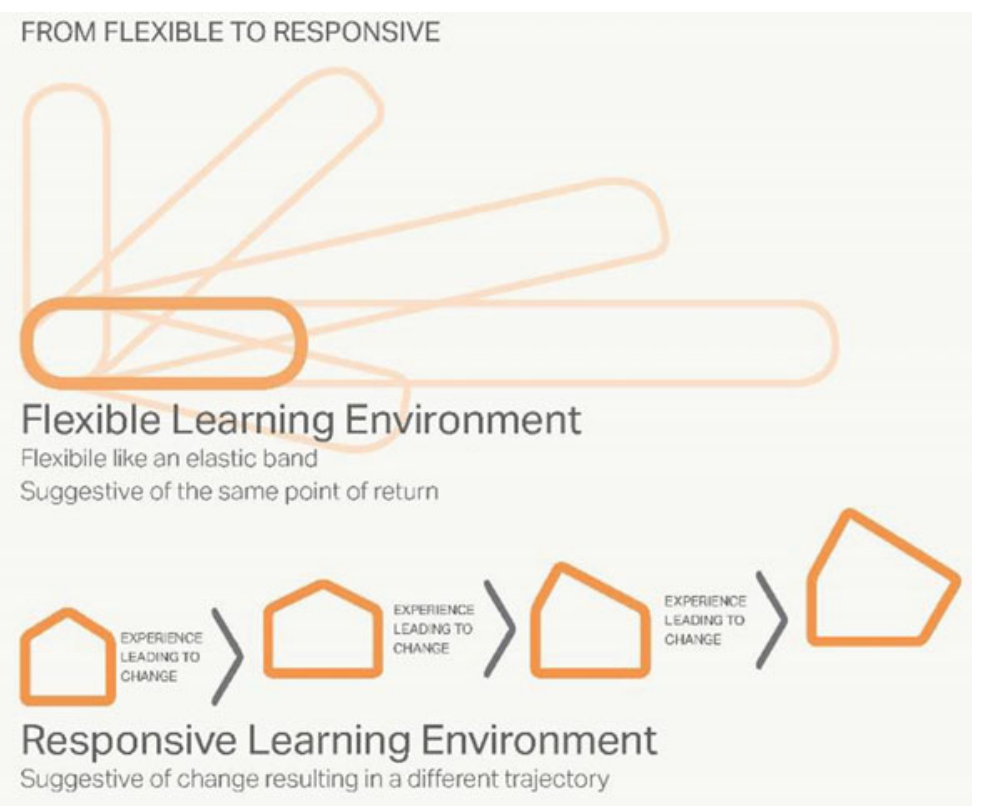

Fig. 3 From flexible to responsive

Architects design school buildings to serve pedagogical and cultural learning purposes, but when a school becomes framed as a potential environment, the relationship between the built environment and the community it serves becomes far more complex, loaded with possibilities. This equation is partly dependent on those that use the space to realise and see its potential (pay attention to it). It is also reliant on architects and designers privileging the influential elements that drive behaviour, such as sensory considerations. Lang reinforces this point; 'built environments will not accommodate people's needs until we integrate what we know and are learning about human experience into their design and composition' (1987, p. 102). This results in prioritising lived experience over (or at least placing it on par) with aesthetics.

\section{Situated Cognition Limitations for Teacher Spatial Interactions}

Whilst acknowledging the importance of the principles advanced by this branch of cognitive psychology, this chapter is not a critique of the academic field. That said, it is recognised that it is important not to overstate the findings of cognitive psychologists in the context of teacher spatial competency by considering their claims as a singular principle. These principles of cognitive psychology are relevant to better understanding TSC but do not represent a cohesive framework for understanding the 
phenomenon. To give an example, consider the assertion that certain visual inputs prime motor activity. A commonly used illustration of this could be a door frame that suggests the act of walking through from one space to another. The simple act of even noticing the door frame requires multiple facilities of knowledge; sense perceptions are needed to take in light waves and interpret them; reason is needed to make sense of the data input; memory checks the current sensory perception again prior experiences; in addition, emotions may be employed as part of this interpretation. All of these make the experience unique to the individual. Wilson (2002), in her examination of the six primary claims of situated cognition, asserts that this type of interaction (door and walking) is more sophisticated and that 'information about the nature of the external world is stored for future use without strong commitments on what that future use may be' (2002, p. 632). Wilson argues that each cognitive arena should be assessed 'according to its own merits'. Wilson's paper, whilst not a rebuttal, disentangles and evaluates the primary claims of cognitive psychologists, concluding that all need to be evaluated in terms of 'the range of their applicability' (2002, p. 635).

The very nature of a cognitive understanding of the environment-teacher equation is that the variables are as variant as the places and actors within them and invites a cautionary approach that is careful not to misrepresent the case.

\section{A Teacher Spatial Competency Conceptual Framework}

\section{Teacher Situated Environmental Imagination}

To bring together the concepts of spatial practice and situated cognition as a helpful framework for articulating how teachers and environments interact, a concept of a teacher's 'situated environmental imagination' has been developed. This concept brings together the three key domains of a teacher's spatial practice; that is teacher place, practice and thinking. The framework addresses the issues inherent to spatial competencies that are constantly in flux.

Drawing on theories from Kant, Heidegger, Soja and Hegel, and through a longestablished theorisation of architectural historiography articulated by Hays (2016), the triadic of spatial practice (the perceived, conceived and lived) also must involve the "gap", or the liminal space in-between the three; a cognitive response which is environmentally situated, socially produced and which determines, regulates and legitimises the lived experience. This response is the link between the different elements that are inherent in every spatial interaction. Interesting to teacher practice, this space is productive (i.e. it moves forwards) and informs the relative relationships between all the elements that contribute to a teacher's spatial competency.

This 'environmental imagination' is multilayered and interdependent. It is cognitively situated or embodied in the environment and it interacts with (and mediates 


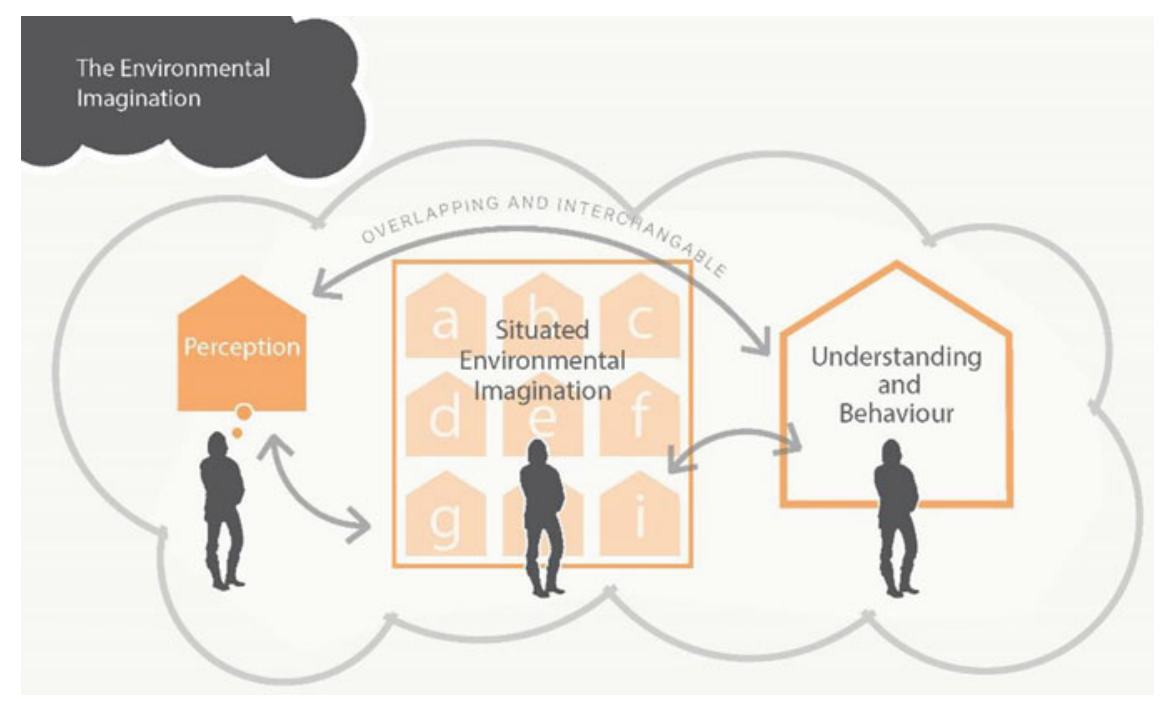

Fig. 4 The environmental imagination

between) a teacher's perception, knowledge and understanding of space, which in turn leads to measurable behaviours associated with spatial competency in the classroom (Fig. 4).

It has an ontological perspective and claim; that architecture exists and 'is' both materially and in the situated environmental imagination of people who perceive it and ultimately use it. Furthermore, something about learning through the nature, the presentness of school architecture becomes known; but the situated imagination also makes and re-makes the concept of teaching and learning in the mind of those using the buildings. The imagination is constantly in flux. It goes beyond simple experience to recognition.

\section{Sensory Information}

To understand more fully; the first consideration, accepting the impact of mediating factors such as prior experience, is human intuition (perception) which synthesises aesthetic experiences: that is, the appearance of the architecture or built environment on a sensory level (Fig. 5).

This experience on its own can be limiting. An individual can sense and feel a place, but that information on its own is meaningless. It is purely sensory information. The experience is mediated by the cognitive imagination (knowledge) and a person's mental capacity to visualise. It is still subjective, informed by prior instruction and education about the environment: it goes beyond intuition to recognition, rooted in memory, prior encounters and conceptualisations. That architecture has a mnemonic 
Fig. 5 Sensory information and perception

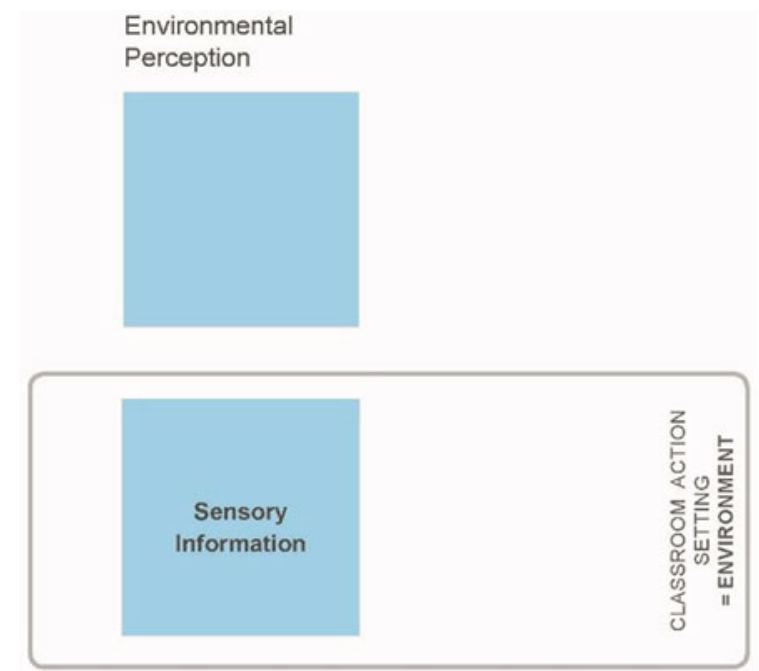

function, it follows that it operates as a 'cognitive map' (Hays, 2016) for the person experiencing the space. The imagination negotiates a schema to organise the array of un-coded sensations. It also needs understanding to turn something purely sensual and material into a cognitive concept. This imaginative element then, in turn, leads to an understanding (conception) of space, which ultimately drives spatial behaviour. An individual's understanding deploys perceptions, categories and cognitive conceptions in an interaction that is informed by this trinitarian architectural interaction. This is an interlocked process in constant flux and anchored by the imagination: they are mutually dependent; they inform each other.

\section{Learned and Instinctive Responses}

The non-conscious schemas can be stimulated by 'primes' (Goldhagen, 2017), defined as an environmental stimulus that of itself influences a person's subsequent thoughts and actions (for example, a pungent drain). This is a physiological response, not learned. Alternatively, a (non-conscious) schema can also be constructed from environmental 'metaphors', memory and prior experiences. These responses are learned. Both these categories of cognitive response enable people to connect meaning and associations by drawing from one context and applying it to another (Fig. 6).

This, of course, raises the question of how these metaphors and primes can be employed by both designers and teachers to manipulate or encourage certain types of behaviour. They are in effect schemas. They help individuals understand abstract ideas and concepts and connect them with their lived experiences. Their beliefs and identities are embedded in these experiences. 
Fig. 6 The cognitive interpretation of learned and instinctive responses

\section{Situated \\ Environmental \\ Imagination}

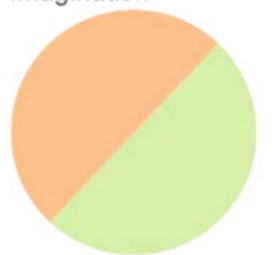

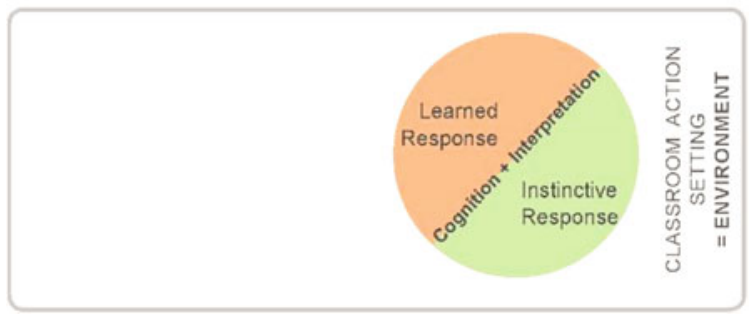

\section{Cognition and Interpretation}

All humans interact with space. All teachers, whatever their experience or proficiency, use classrooms as a tool to work within whilst teaching students and promoting learning. Similarly, students are also situated in the space. These interactions are a kaleidoscope of sensory data, 'real-time' cognitions, perceptions, actions and social interactions and are impacted by, and mutually dependent upon, individual and cultural influences, as well as motivational needs. Every individual experience similar levels of complexity as all are all 'situated' in their environment (Robbins \& Aydede, 2009). The organisation of the data and resulting behaviour are constantly being reimagined, refined and honed. Therefore, for the teacher perceived as spatially incompetent (or unable/unwilling to utilise a classroom's affordances), this should be understood within the context of the multitude of cognitive interactions that they are processing. Furthermore, it could be stated that this teacher might be spatially competent within the capacity of their perceptions, emotions and experiences. The choices presented by the space and associated primes and cues may not be perceived at all, or even if acknowledged, dismissed precisely because of 'high' competence behaviour triggered by different and unique motivations and associations of an individual.

Wilson (2002) provides a foothold into this complex equation. In breaking down the six main claims of situated cognition, she recognises that whilst cognition is situated, it is also influenced by time-pressure and 'real-time'. She states; 'More sophisticated forms of real-time situated cognition can be seen in any activity that involves continuous updating of plans in response to rapidly changing conditions' (p. 268). 
This could be a description of a rapidly changing classroom and suggests that an opportunity to predict or plan outside of the reactive environment could be of assistance. When under pressure where people are forced to work 'online' (reacting to the present), Wilson suggests they use a range of strategies to cope, including 'preloaded representations' acquired through prior learning; selectively interacting with the environment, leaving unknown elements to be encoded later and altering the environment to lighten the cognitive load. Furthermore, Wilson promotes further investigation into the concept of body-based 'off-line cognition', where mental imagery (imagining external events), working and episodic memory (tied to bodied experiences of the world), implicit memory (automating responses) and reasoning and problem-solving are considered as ways to understand how the body influences or even controls the mind. This is important as it implies a framework for working with teachers before their entry into new classroom spaces.

\section{Cognition and Memory}

Memory contributes to the human autobiographical sense of self and identity which is associated with the experiences had in lived environments throughout a lifetime.

This idea is reinforced by Goldhagen; 'We cannot recall a memory from our past without revisiting at least some elements of the place where the original event occurred-if not consciously, then at least unconsciously' (2017, p. 85). The recollection of a loved primary teacher, for example, involves visualising that person in the classroom spaces experienced as a child. Life events such as graduation are thought of in terms of the place in which it occurred. Similarly, when a teacher considers the cognitive task of teaching, they think of their classroom, the school, even the activities suggested by the affordances available to them to enable them to teach. The act of teaching, the experience, is embedded in the place in which it occurs. Memory allows humans to adapt to new environments and to learn new values through a process of understanding that comes from reinforced, prior experience. How teachers respond to a new learning environment, for example, is a result of their response to the sensory information and patterns present in the space, and how they categorise these elements based on the associations they have built up over time, backed up by any reinforcements they may have experienced. Lackney's study and Gislason are a good example of research that demonstrates and provides evidence for this pattern of behaviour (Gislason, 2010; Lackney, 2008). What individuals choose in terms of action in response to a setting is the result of their experiences of different places and the objects within them. The actions are taken, therefore, become the experience and continually feed into a personal narrative and identity. This person-environment relationship is a dynamic one. 


\section{Cognition and Affordances or Environmental Stimuli}

The term 'affordances' was coined by Gibson (1977) and infer that different patterns within the built environment afford or suggest different behaviours and aesthetic experiences. They are a function of both social convention and life history (Chemero, 2003). However, it is the 'experiential opportunities' (Goldhagen, 2017), the what people choose to focus on or act upon (either consciously or unconsciously) offered by a places' affordances, that becomes a point of focus for teachers.

Interestingly, Lackney summed up one element of his findings in this way: 'During individual interviews when teachers were asked to describe their perceptions of their school, they tended to identify sensory stimulation concerns, specifically regarding thermal comfort and air quality of the school, followed by problems of noise' (Lackney, 2008, p. 16). That these educators chose to focus on specific sensory concerns would not come as a surprise to those versed in situated cognition theory, or indeed most teacher practitioners in schools today.

Information about the environment is obtained through perceptual processes. This is active and purposeful. Neisser (1976) said, 'it is where cognition and reality meet'. These processes are guided by schemas which are partially innate, partially learned which, in turn, guide emotional responses and ultimately actions and behaviour. The information obtained from the environment has symbolic qualities (giving it meaning), ambient qualities (evoking emotional responses) and motivational messages (stimulating need). Gibson's ecological theory of perception (2015) hypothesises that a wide range of sensory data is always available to us but people only attend to what they know and are motivated to recognise, based on their prior experiences within the environment. More recent studies emphasise that this model of human cognition is not a sequential process. Goldhagen (2017) describes this as the out there of environmental perception that is intermeshed with the in here of cognition and interpretation, thereby resulting in out here action (Fig. 7). Therefore, the environmental stimulus (the 'out there') is not separated from the 'in there' of cognition, rather the elements are inherently interlinked and intermeshed. No boundaries are separating them. In other words, individuals are already, or always (bodily) engaged with the environment. The physical environment that is inhabited is irretrievably linked to human experiences and memory. The individual, and the spaces in which they enact their life is constantly in motion.

Lived experiences are therefore inherently influenced by the environment. What is chosen to be registered consciously or unconsciously is based on the opportunities that are offered by the affordances within the environment. Equally, however, these choices are also embedded in experiences and memory. 


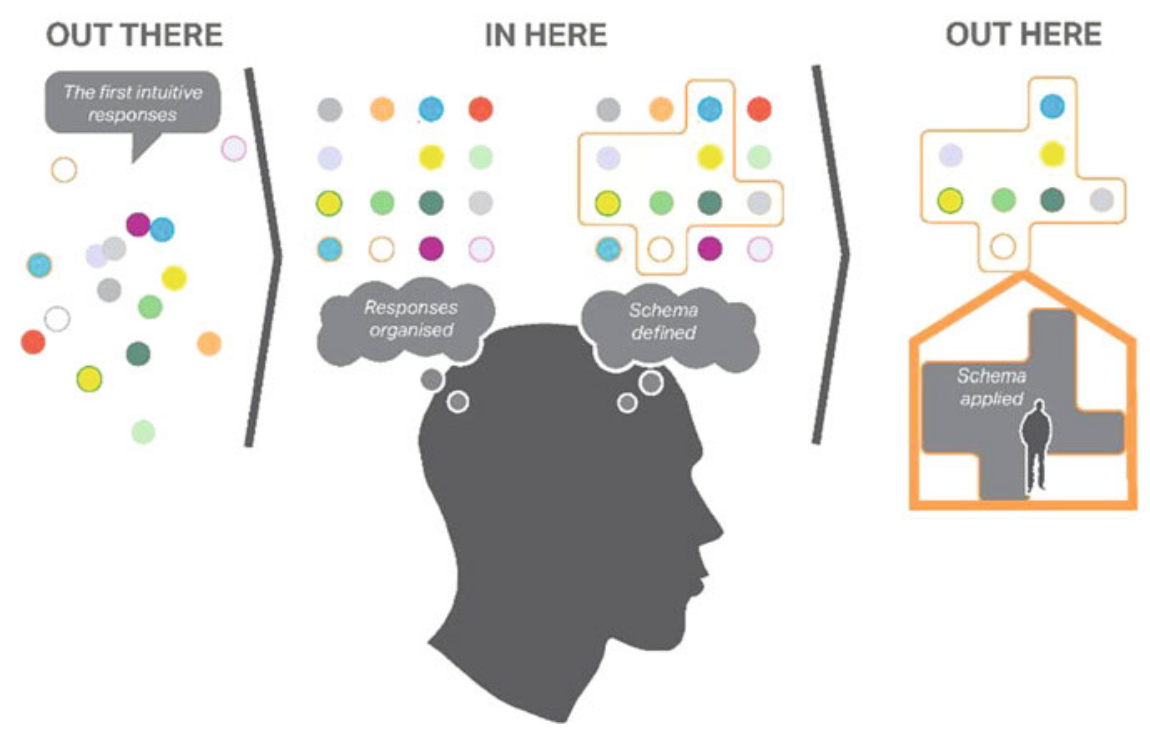

Fig. 7 After Goldhagen: 'out there, in here, out here'

\section{Action Settings}

The term 'action settings' has been utilised by Goldhagen (2017) to describe the animated nature between the environment and human behaviour. Barker (1968) used a similar term 'behaviour settings' to describe the relationship between the built environment and the standing or recurrent behaviour that takes place in it. Whilst helpful, Goldhagen prefers the term 'action settings' to 'emphasise the agency of humans who make choices within the environments they encounter' (p. 196). This ecological view on human agency is directly related to the environmental conditions through which it is enacted. This can be therefore interpreted as an attribute that can be enacted, rather than an innate ability (Biesta, Priestley, \& Robinson, 2015).

In summary, humans perform in an environment. They assess its ability to help them achieve their goals; they consciously and unconsciously react to primes and metaphors, influenced by memories that make up the numerous schemas stored in their brains; they, therefore, shape the environment and how it interacts with them. These 'action settings' are places that are not 'mute' but register non-consciously and consciously with the individual (in their imagination), with experiential opportunities offered through its affordances. How they respond is influenced by who they are; the range of responses are as individual as people are (Fig. 8). Human behaviour is influenced by what their conscious and non-conscious brain chooses to pay attention to. It does so using selection principles that it has developed over years of experience in the classroom, as a student, as a student-teacher and as a professional (Goldhagen, 2017). This transaction is determined by the individual's physical presence in the space; the materiality of the space (which help them decide how to engage with it); 


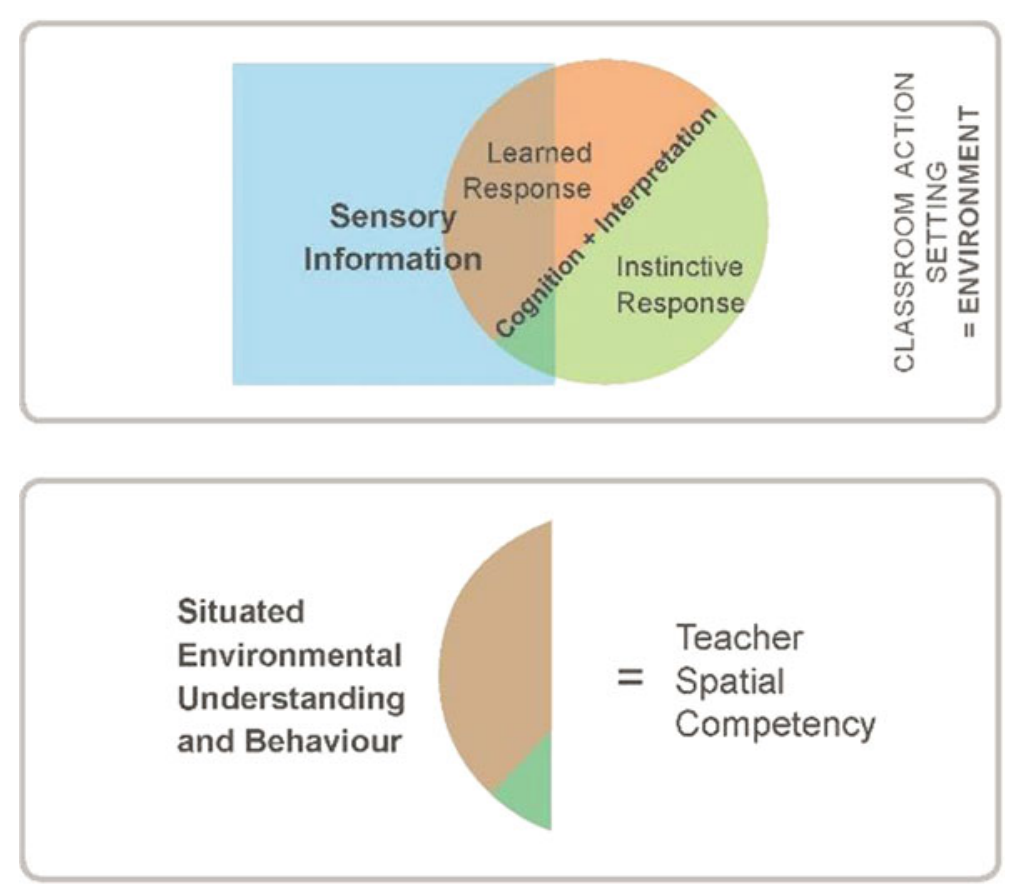

Fig. 8 The components of TSC in a classroom action setting

their perceived assessment of the spaces' usefulness to their goal (to teach); and importantly, if they perceive the environment and its affordances worthy of their attention. This, of course, relies on their ability to understand what space can 'do'. Ulrich Neisser (1976) describes this as 'anticipatory schemata'. People can only perceive what they know how to find.

This transactional, situated cognitive behaviour between individuals and the built environment provides the enabling and inhibiting structure for cultural norms of behaviour. Therefore, the environment is the cornerstone of human life. It shapes a person and their sense of identity and is interwoven with their past, present and future. It is a function of human needs and competencies. Richard Neutra argued 'In that our environment is a form of education, the architect can be considered an educator. Every building schools our senses or shapes our perspective in some degree' (as cited in Nelson \& Sundt, 1993, p. 2).

Most human behaviour is accepted as 'reasonable' and 'planned' and follows patterns that are dependent on intentionality and perception (Ajzen, 1985). Teachers' place perception is a matter of past experiences, current environments and imagined futures. These past, current and future place experiences all operate within system constraints. What is important is that those who use the educational places, teachers and students, are taught to see or to be aware of the impact of the environment, and their own experiences, to maximise the potentiality of the setting and make 
productive choices within the space. When a learning environment is seen as an action setting, the response should be a desire to understand what (already) occurs in school buildings every day. This, in turn, leads to purposeful pedagogical and environmental design, both which shape each other and drives change.

\section{Teacher Spatial Competency Observation and Method}

The conceptualisation of the concepts involved with teacher spatial competency suggests that this is a professional teaching competency and skill that has to date sat in the background of teacher professional practice. This has led to a conceptual framework for measuring teacher spatial behaviours, with the further potential to relate these behaviours to student learning outcomes. This framework has defined key guiding principles that, (to borrow from the principles of evaluation theory), '...organises, categorises, describes, predicts, explains, and otherwise aids in understanding and controlling...' (Shadish, Cook, \& Leviton, 1991) spatial competency skills.

The conceptual framework requires validation. The best way to do this is to observe actual teaching spatial practice to establish if this conceptualisation is a realistic interpretation of how teachers interact with their environment. If so, validation must also establish that the framework assists in better understanding how this interaction might lead to improved teaching and therefore better student educational experiences. This is the focus of the next phase of the research.

As an observation tool, in the first instance, a three-tiered system has been devised. A 'Teacher Spatial Competency Instrument' (TSCI) has been developed with the task of measuring observable practitioner action related to spatial competency behaviour. The observed behaviour is contextualised using a specialist app that has been developed to record all sensory and material data concerning teacher action settings; their classrooms and school. This data is then visually and verbally analysed by individual teachers through semi-structured interviews aimed at interpreting personal cognitive responses, the situated environmental imagination, verbalised as perception. This interpretation is conducted through the lens of learned (prior) experiences and instinctive responses. It recognises the unique spatial skills of individuals and provides a logic for linking the main proposition to data relating to teacher spatial practice and student learning outcomes.

\section{Conclusion}

It is proposed that a situated environmental imagination is a conceptual framework that can be explored to facilitate teacher spatial competencies that effect improved learning for their students (Fig. 9). 


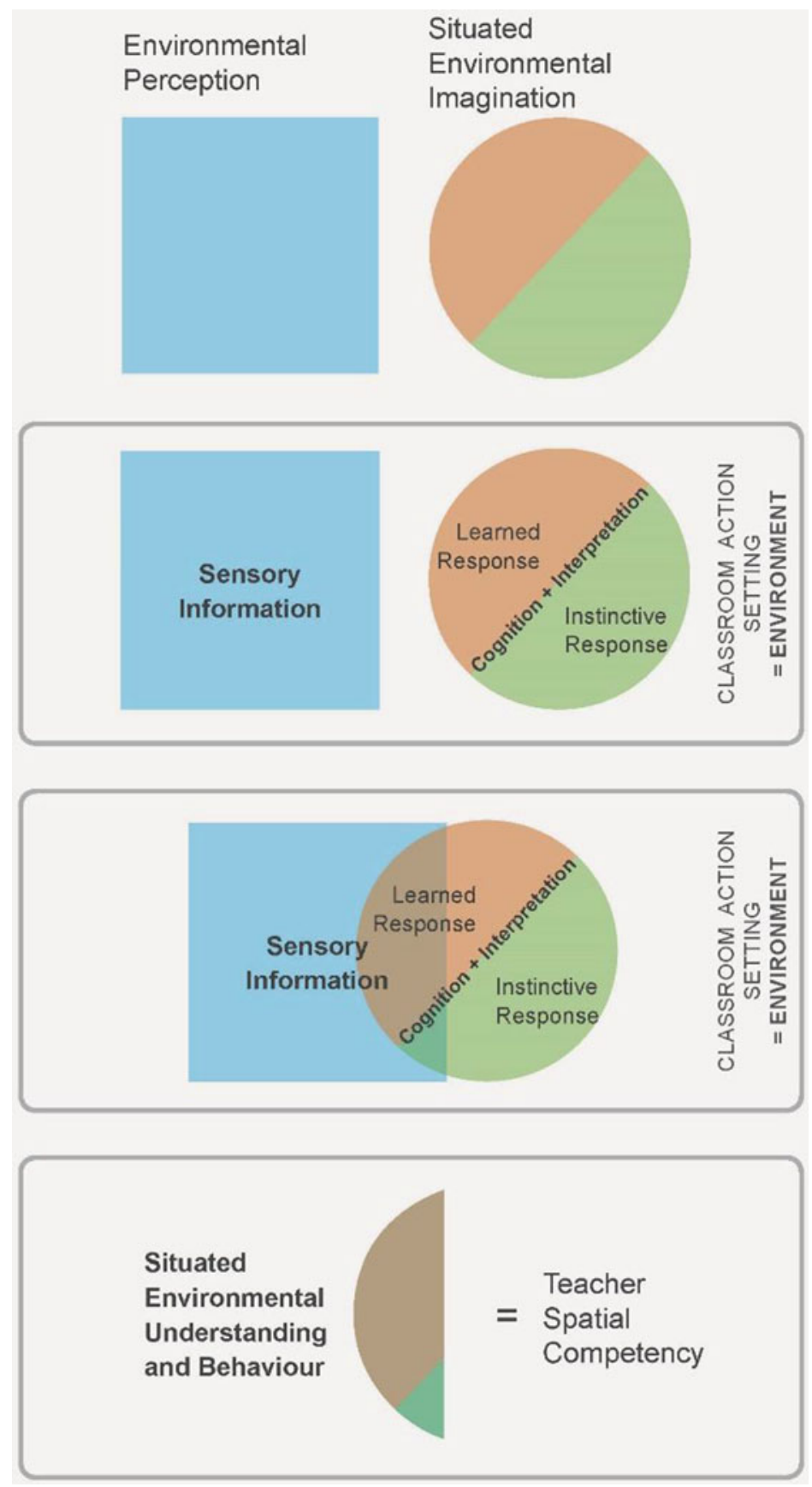

Fig. 9 Teacher spatial competency conceptual framework 
The concept can be summarised; the perception of a teacher towards their teaching space (influenced by sensory and symbolic affordances) leads (in their situated environmental imagination) to a mental picture (based on prior encounters, social cues and culture) that is shaped into a schematisation of the space that informs their understanding and knowledge of that environment and influences their behavioural response to it. Each interaction within the space informs the next.

The hypothesis is that this cognitive transaction within the environment is responsive and that what appears to be almost predetermined spatial behaviour in a teacher can be influenced by new knowledge, 'off-line' pre-loaded representations and situated experiences (Wilson, 2002). This ultimately implies that teacher spatial competency can be enhanced to positively influence student learning outcomes through intervention strategies.

This conceptualisation is giving representation and form to what has seemed unrepresentable. It is expressing teacher response to place that is not yet articulated but has rather been seen as 'just the way it is'. It is argued that the teacher, the person who encounters the learning space, experiences a situated environmental 'imaginative' response that is manifested in spatial behaviour and competency. Every encounter is individual but also utilises a collective and social cognition about space. The observation proposal aims to expose this interaction, articulate it, advance proposed interventions (such as 'offline' spatial planning or pre-loading representations) and observe its effect on teaching and learning.

Acknowledgements Data utilised in this research was obtained in adherence to the required ethical protocol of the author's host institution. All images and diagrams are the property of the author, or the author has obtained consent to use them from the appropriate copyright owner.

\section{References}

Ajzen, I. (1985). From intentions to actions: A theory of planned behaviour. Action control: From cognition to behavior (pp. 11-39). Heidelberg: Springer.

Barker, R. G. (1968). Ecological psychology: Concepts and methods for studying the environment of human behavior. Stanford: Stanford University Press.

Barker, R. G., \& Gump, P. (1964). Big school, small school: High school size and student behaviour. Stanford: Stanford University Press.

Barsalou, L. W. (2008). Grounded cognition. Annual review of psychology, 59, 617-645. https://doi. org/10.1146/annurev.psych.59.103006.093639.

Benade, L. (2017). Is the classroom obsolete in the 21 st century? Educational Philosophy \& Theory., 49(8), 796-807. https://doi.org/10.1080/00131857.2016.1269631.

Biesta, G., Priestley, M., \& Robinson, S. (2015). The role of beliefs in teacher agency. Teachers and Teaching: Theory and Practice, 21(6), 624-640. https://doi.org/10.1080/13540602.2015.104 4325.

Bradbeer, C. (2016). Working together in the space-between. In W. Imms, B. Cleveland, \& K. Fisher (Eds.), Evaluating learning environments (pp. 75-90). Netherlands: Springer.

Byers, T., Imms, W., \& Wheaton, A. (2015). Empirical evidence that supports changes to pedagogical practice and tracks learning gains in contemporary and technology-enabled learning 
environments. Paper presented at the ACER Excellence in Professional Practice Conference Sydney.

Byers, T., Mahat, M., Liu, K., Knock, A., \& Imms, W. (2018). A systematic review of the effects of learning environments on student learning outcomes-technical report 4/2018. Retrieved from Melbourne: http://hdl.handle.net/11343/216293.

Casey, E. S. (2009). Getting back into place: Toward a renewed understanding of the place-world. Bloomington: Indiana University Press.

Chemero, A. (2003). An outline of a theory of affordances. Ecological Psychology, 15(2), 181-195.

Fisher, K. D. (2004). Revoicing classrooms: A spatial manifesto. Forum, 46(1), 36-38. https://doi. org/10.2304/forum.2004.46.1.8.

Fisher, K. D. (2005). Linking pedagogy and space: Planning principles for Victorian schools based on the principles of teaching and learning. Retrieved from Melbourne: http://www.eduweb.vic. gov.au/edulibrary/public/assetman/bf/Linking_Pedagogy_and_Space.pdf.

Gibson, J. J. (1966). The senses considered as perceptual systems. London: Allen \& Unwin.

Gibson, J. J. (1977). The theory of affordance. In R. Shaw \& J. Bransford (Eds.), Perceiving, acting, and knowing: Toward an ecological psychology (pp. 67-82). New Jersey: Hillsdale.

Gibson, J. J. (2015). The ecological approach to visual perception. New York: Psychology Press.

Gislason, N. (2010). Architectural design and the learning environment: A framework for school design research. Learning Environments Research, 13(2), 127-145. https://doi.org/10.1007/s10 984-010-9071-x.

Goldhagen, S. W. (2017). Welcome to your world: How the built environment shapes our lives. New York: Harper Collins Publishers.

Hattie, J. (2009). Visible learning: A synthesis of over 800 meta-analyses relating to achievement. New York: Routledge.

Hattie, J. (2012). Visible learning for teachers: Maximizing impact on learning. New York: Routledge.

Hays, K. M. (2016). Architecture's appearance and the practices of imagination. Log, 37, 205-213. Retrieved from https://www-jstor-org.ezp.lib.unimelb.edu.au/stable/26324734.

Higgins, S., Hall, E., Wall, K., Woolner, P., \& McCaughey, C. (2005). The impact of school environments: A literature review produced for the Design Council, Newcastle.

Hildebrand, G. M. (1999). Con/testing learning models. Paper presented at the Australian Association for Research in Education and New Zealand Association for Research in Education Conference, Melbourne. https://www.aare.edu.au/data/publications/1999/hil99582.pdf.

Johnson, M. (1987). The body in the mind: The bodily basis of meaning, imagination, and reason. Chicago: University of Chicago Press.

Kirk, W. (1990). Historical geography and the concept of the behavioural environment. In F. W. Boal \& D. N. Livingstone (Eds.), The Behavioural Environment: Essays in reflection, application and re-evaluation (pp. 38-50). London: Routledge.

Koffka, K. (1935). Principles of gestalt psychology. New York: Harcourt, Brace \& Co.

Lackney, J. A. (2008). Teacher environmental competence in elementary school environments. Children, Youth and Environments, 18(2), 133-159.

Lang, J. (1987). Creating architectural theory. New York: Van Nostrand Reinhold Co.

Lawton, M. P. (1977). An ecological theory of ageing applied to elderly housing. Journal of architectural education, 31(1), 8-10. https://doi.org/10.1080/10464883.1977.11102585.

Lefebre, H. (1991). The production of space. Oxford: Blackwell.

Lewin, K. (1936). Principles of topological psychology. In McGraw-Hill publications in psychology.

Lippman, P. C. (2010). Can the physical environment have an impact on the learning environment? CELE Exchange. Centre for Effective Learning Environments(11-14), 1-5. https://doi.org/10. $1787 / 5 \mathrm{~km} 4 \mathrm{~g} 21 \mathrm{wpwr} 1-\mathrm{en}$.

Massey, D. (2005). For space London: Sage.

Merrifield, A. (2006). Henri Lefebvre: A critical introduction. New York: Routledge. 
Moore, G. T. (1986). Effects of the spatial definition of behavior settings on children's behavior: A quasi-experimental field study. Journal of Environmental Psychology, 6(3), 205-231. https://doi. org/10.1016/S0272-4944(86)80023-8.

Moustakas, C. (1994). Phenomenological research methods. Thousand Oaks: Sage.

Nair, P. (2011). The classroom is obsolete: It's time for something new. Education Week, 29.

Neisser, U. (1976). Cognition and reality. Principles and implication of cognitive psychology. New York: W H Freeman/Times Books/ Henry Holt \& Co.

Nelson, D., \& Sundt, J. (1993). Changing the architecture of teachers' minds. Children's Environments, 10(2), 159-169.

New Zealand Ministry of Education. (2014). The Ministry of Education's statement of intent 2014 2018. Wellington, New Zealand: New Zealand Ministry of Education.

Oblinger, D. G. (2006). Learning spaces. In D. G. Oblinger (Ed.). Retrieved from https://www.edu cause.edu/ir/library/pdf/PUB7102.pdf.

OECD. (2013). Innovative learning environments: OECD Publishing.

Owens, R., \& Valesky, T. (2007). Organizational behavior in education: Adaptive leadership and school reform., Allan \& Bacon. Boston: Pearson/Allyn \& Bacon.

Perin, C. (1970). With man in mind: An interdisciplinary prospectus for environmental design. Cambridge: MIT Press.

Pointon, P., \& Kershner, R. (2000). Making decisions about organising the primary classroom environment as a context for learning: the views of three experienced teachers and their pupils. Teaching and Teacher Education, 16(1), 117-127. https://doi.org/10.1016/S0742-051X(99)000 43-8.

Robbins, P., \& Aydede, M. (2009). The Cambridge handbook of situated cognition. Cambridge: Cambridge University Press.

Saltmarsh, S., Chapman, A., Campbell, M., \& Drew, C. (2014). Putting "structure within the space": Spatially un/responsive pedagogic practices in open-plan learning environments. Educational Review, 67(3), 315-327. https://doi.org/10.1080/00131911.2014.924482.

Shadish, W., Cook, T., \& Leviton, L. (1991). Foundations of program evaluation. Thousand Oaks: Sage.

Soja, E. W. (1989). Postmodern geographies: The reassertion of space in critical social theory. London: Verso.

Swartz, J., \& Martin, W. (1997). Ecology psychology theory: Historical overview and application to educational ecosystems. In J. Swartz, W. Martin, \& J. Swartz-Kulstad (Eds.), Applied ecological psychology for schools within communities: Assessment and intervention (pp. 1-25). New York: Routledge.

Tanner, C. K. (2009). Effects of school design on student outcomes. Journal of Educational Administration, 47(3), 55-73. https://doi.org/10.1108/09578230910955809.

Tyack, D., \& Tobin, W. (1994). The "grammar" of schooling: Why has it been so hard to change? American Educational Research Journal, 31(3), 453-479. https://doi.org/10.3102/000283120 31003453.

Weinstein, C. S. (1981). Classroom design as an external condition for learning. Educational Technology, 21(8), 12-19.

Wilson, M. (2002). Six views of embodied cognition. Psychonomic Bulletin \& Review, 9(4), 625636. https://doi.org/10.3758/bf03196322.

Woolner, P., Clark, J., Laing, K., Thomas, U., \& Tiplady, L. (2012). Changing spaces: Preparing students and teachers for a new learning environment. Children Youth and Environments, 22(1), 52-74. https://doi.org/10.7721/chilyoutenvi.22.1.0052.

Vicky Leighton (Australia) is currently the Head of Art at the Innovative Learning Environments \& Teacher Change Project partnership school, Anglican Church Grammar School in Brisbane, Australia, and vice-chair for The Churchie National Emerging Art Prize in Australia. Vicky is undertaking her Ph.D. research as part of the Innovative Learning Environment and 
Teacher Change project at The University of Melbourne. Through the evaluation of teacher spatial thinking, literacy and competency, this research focuses on finding evidence on how (if at all) classroom spaces sculpt or influence a teacher's professional practice.

Open Access This chapter is licensed under the terms of the Creative Commons Attribution 4.0 International License (http://creativecommons.org/licenses/by/4.0/), which permits use, sharing, adaptation, distribution and reproduction in any medium or format, as long as you give appropriate credit to the original author(s) and the source, provide a link to the Creative Commons license and indicate if changes were made.

The images or other third party material in this chapter are included in the chapter's Creative Commons license, unless indicated otherwise in a credit line to the material. If material is not included in the chapter's Creative Commons license and your intended use is not permitted by statutory regulation or exceeds the permitted use, you will need to obtain permission directly from the copyright holder. 